$11-1-2011$

\title{
Control Balanced Designs Involving Sequences of Treatments
}

Cini Varghese

Indian Agricultural Statistics Research Institute, cini_v@iasri.res.in

Seema Jaggi

Indian Agricultural Statistics Research Institute, seema@iasri.res.in

Follow this and additional works at: http://digitalcommons.wayne.edu/jmasm

Part of the Applied Statistics Commons, Social and Behavioral Sciences Commons, and the Statistical Theory Commons

\section{Recommended Citation}

Varghese, Cini and Jaggi, Seema (2011) "Control Balanced Designs Involving Sequences of Treatments," Journal of Modern Applied Statistical Methods: Vol. 10 : Iss. 2 , Article 21.

DOI: $10.22237 /$ jmasm/1320121200

Available at: http://digitalcommons.wayne.edu/jmasm/vol10/iss2/21

This Regular Article is brought to you for free and open access by the Open Access Journals at DigitalCommons@WayneState. It has been accepted for inclusion in Journal of Modern Applied Statistical Methods by an authorized editor of DigitalCommons@WayneState. 


\title{
Control Balanced Designs Involving Sequences of Treatments
}

\author{
Cini Varghese \\ Seema Jaggi \\ Indian Agricultural Statistics Research Institute, \\ New Delhi, India
}

Designs involving sequences of treatments for test vs. control comparisons are suitable for research in which each experimental unit receives treatments over time in order to compare several test treatments to one (or more) control treatment(s). These designs can be advantageously used in screening experiments and bioequivalence trials. Three series of such designs are constructed in incomplete sequences wherein the first class of designs is variance balanced while the other two classes of designs are partially variance balanced for test versus test comparisons of both direct and residual effects of treatments.

Key words: Change over designs, direct effects, residual effects, control balance, variance balance, partial balance, bioequivalence trials.

\section{Introduction}

Change over designs (COD) are designs in which each experimental unit receives one or more treatments, one at a time, in successive periods. These designs also known as repeated measurement designs, crossover trials and designs involving sequences of treatments; they have been widely used in several fields of research, notably in nutrition experiments with dairy cattle, clinical trials, educational/ learning experiments, long-term agricultural field experiments and bioequivalence trials. A COD is one of the most suitable designs for experiments with animals as experimental units (different treatments) are often applied to the same animal in different periods. The distinguishing feature

Cini Varghese is a Senior Scientist in Agricultural Statistics. Her research interests include: construction and analysis of experimental designs, characterization properties of experimental designs, web generations of designs and software development. Email her at: cini_v@iasri.res.in. Seema Jaggi is a Senior Scientist in Agricultural Statistics. Her research interests include: design of experiments, statistical computing, statistical techniques in agricultural research, web solutions to experimental designs and analysis. Email her at: seema@iasri.res.in. of such an experiment is that any treatment applied to a unit in a certain period influences the responses of the unit not only in the period of its application but also leaves residual effects in the succeeding periods.

In some experimental situations involving treatment sequences, researchers are interested in comparing several new (test) treatments to one (or more) established (standard or control) treatment(s) rather than in all pairwise comparisons. That is, the researcher is interested in drawing inferences based on a subset of comparisons among treatments; special designs giving more importance to test versus control comparisons must be developed to meet requirements in these cases. Using such a design would allow a researcher to screen out best test treatments as compared to existing control treatment(s). This type of design is also useful in bioequivalence trials (such as veterinary medicinal trials) where a set of test formulations are to be compared to established reference formulations before sanctioning the marketing patent for a newly produced formulation.

Usage of CODs for test versus control comparisons began with the introduction of control balanced CODs by Pigeon and Raghavarao (1987), who derived a set of necessary conditions for the existence of control balanced CODs (CODs balanced for test vs. control comparisons). They provided construction methods using existing balanced 


\section{VARGHESE \& JAGGI}

CODs, pairwise balanced designs and also the method of differences. Majumdar (1988) obtained some optimal control balanced designs involving sequences of treatments when number of treatments is less than the number of periods and showed that the designs can be constructed from existing strongly balanced uniform circular/non-circular CODs in test treatments by changing some test treatment labels into control. Koch, et al. (1989) studied a two-period COD for the comparison of two active treatments and placebo. Hedayat and Zhao (1990) investigated two classes of efficient CODs for the purpose of comparing several test treatments to a control treatment when the number of periods is two.

Ting (2002) constructed optimal designs for the estimation of control-test treatment contrasts in a COD set up. Aggarwal, et al. (2004) developed families of CODs for test versus control comparisons by juxtaposing Williams (1949) Latin square(s) by using block contents of various classes of balanced incomplete block designs and an orthogonal array of type 1 and strength 2. Aggarwal, et al. (2004) showed that these designs are optimal. Hedayat and Yang (2005) provided some construction methods for obtaining control balanced CODs. Most of these designs are balanced for carryover effects, but require a large number of experimental periods as well as subjects. Hedayat and Yang (2005) also characterized a class of designs that are optimal for comparing several test treatments with a control. Yang and Park (2007) obtained efficient CODs for comparing test treatments with a control treatment with three periods. Aggarwal and Jha (2009) suggested methods for constructing CODs to compare $\mathrm{v}$ test treatments with a control treatment when the number of periods is no larger than $\mathrm{v}+1$.

This study constructed a series of control balanced designs involving sequences of treatments in three periods that are variance balanced. Another class of partially balanced designs involving incomplete sequences based on mutually orthogonal Latin squares was also obtained. In addition, a third series of control balanced designs in incomplete sequences of two distinct sets of treatments was obtained to compare one set of test treatments with two control treatments. Some definitions are given below that would be used in the subsequent sections.

Definitions

The following designs relate to studies involving treatment sequences.

\section{Control Balanced Design}

A control balanced COD for $\mathrm{t}+\mathrm{c}(=\mathrm{t}$ test $+\mathrm{c}$ control) treatments in $\mathrm{p}$ periods and $\mathrm{n}$ experimental units for test versus control comparisons is said to be balanced in the presence of residual effects, if:

(a) Each test treatment occurs $\omega_{t}$ times and each control treatment occurs $\omega_{\mathrm{c}}$ times in each period;

(b) Each test treatment is immediately preceded by every other test treatment equally often, for example, $v_{t^{\prime}}\left(t \neq t^{\prime}\right)$;

(c) Each control treatment is immediately preceded by every other control treatment equally often, for example, $v_{\mathrm{cc}^{\prime}}\left(\mathrm{c} \neq \mathrm{c}^{\prime}\right)$; and

(d) Each control treatment is immediately preceded by every test treatment and vice versa equally often, for example, $v_{\mathrm{tc}}$.

It may be noted that when $\omega_{\mathrm{t}}=\omega_{\mathrm{c}}$ and $v_{\mathrm{tt}^{\prime}}=v_{\mathrm{cc}}$ $=v_{t c}$, these designs reduce to conventional CODs balanced for first order residual effects.

Variance Balanced Design

A control balanced COD for $\mathrm{t}+\mathrm{c}(=\mathrm{t}$ test $+\mathrm{c}$ control) treatments in $\mathrm{p}$ periods and $\mathrm{n}$ experimental units for test versus control comparisons is said to be variance balanced in the presence of residual effects, if all elementary contrasts pertaining to:

(a) Direct (residual) effects among test treatments are estimated with the same variance, $\mathrm{V}_{\mathrm{tt}^{\prime} \mathrm{d}}\left(\mathrm{V}_{\mathrm{tt}^{\prime} \mathrm{r}}\right)\left(\mathrm{t} \neq \mathrm{t}^{\prime}\right)$; and

(b) Direct (residual) effects among test versus control treatment are estimated with the same variance, $\mathrm{V}_{\text {tcd }}\left(\mathrm{V}_{\mathrm{tcr}}\right)$. 


\section{CONTROL BALANCED DESIGNS INVOLVING SEQUENCES OF TREATMENTS}

\section{Partially Balanced Design}

A control balanced COD for $\mathrm{t}+\mathrm{c}(=\mathrm{t}$ test $+\mathrm{c}$ control) treatments in $\mathrm{p}$ periods and $\mathrm{n}$ experimental units for test versus control comparisons is said to be partially variance balanced with an underlying m-class association scheme in the presence of residual effects, if all elementary contrasts pertaining to:

(a) Direct (residual) effects among test treatments that are $i^{\text {th }}$ associates to each other, are estimated with the same variance $\mathrm{V}_{\mathrm{tt} t^{\prime} \text { id }}\left(\mathrm{V}_{\mathrm{tt}^{\prime} \text { ir }}\right)\left(\mathrm{t} \neq \mathrm{t}^{\prime} ; \mathrm{i}=1,2, \ldots \mathrm{m}\right)$; and

(b) Direct (residual) effects of test and control treatment are estimated with the same variance $\mathrm{V}_{\text {tcd }}\left(\mathrm{V}_{\text {tcr }}\right)$.

\section{Circular Association Scheme}

Let there be $t$ test treatments arranged on the circumference of a circle. For a given treatment, the treatments that appear at $i^{\text {th }}$ positions on its either side are $i^{\text {th }}$ associates $[i=$ $1,2, \ldots,(t-1) / 2$ if $t$ is odd, or $t / 2$ if $t$ is even]. For odd $t$, there are always two $i^{\text {th }}$ associates of each treatment for $\mathrm{i}=1,2, \ldots,(\mathrm{t}-1) / 2$, and for an even $t$ there are two $i^{\text {th }}$ associates of every treatment for $\mathrm{i}=1,2, \ldots,(\mathrm{t}-1) / 2$ and one associate for $i=t / 2$. The arrangement of 7 treatments in a circular association scheme could be:

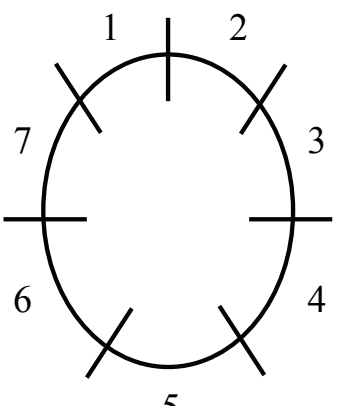

5

The first, second and third associates of the 7 treatments are:

\begin{tabular}{|c|c|c|c|}
\hline Treatment & $\begin{array}{c}\text { First } \\
\text { Associates }\end{array}$ & $\begin{array}{c}\text { Second } \\
\text { Associates }\end{array}$ & $\begin{array}{c}\text { Third } \\
\text { Associates }\end{array}$ \\
\hline 1 & 2,7 & 3,6 & 4,5 \\
\hline 2 & 1,3 & 4,7 & 5,6 \\
\hline 3 & 2,4 & 1,5 & 6,7 \\
\hline 4 & 3,5 & 2,6 & 1,7 \\
\hline 5 & 4,6 & 3,7 & 1,2 \\
\hline 6 & 5,7 & 1,4 & 2,3 \\
\hline 7 & 6,1 & 2,5 & 3,4 \\
\hline
\end{tabular}

Experimental Design 1: Control Balanced Designs Involving Treatment Sequences in Three Periods

Arrange all possible distinct pairs from $\mathrm{t}$ test treatments $\left(2{ }^{\mathrm{t}} \mathrm{C}_{2}\right.$ pairs $)$ excluding the identical pairs in $2{ }^{\mathrm{t}} \mathrm{C}_{2}$ rows of size 2 each; repeat the $2{ }^{t} C_{2}$ pairs 3 times. In the first set, append a column containing all elements as control treatment $(\mathrm{t}+1), 2{ }^{\mathrm{t}} \mathrm{C}_{2}$ times as the first column; in the second set append a column of control treatment $(\mathrm{t}+1), 2{ }^{\mathrm{t}} \mathrm{C}_{2}$ times as the second column and in the third set append a column of control treatment $(\mathrm{t}+1), 2{ }^{\mathrm{t}} \mathrm{C}_{2}$ times as the third column. Juxtapose the three sets, side by side, so that the resulting arrangement has 3 columns and $6{ }^{\mathrm{t}} \mathrm{C}_{2}$ rows. Treating columns as periods and rows as experimental units, this arrangement yields a control balanced COD balanced for first residual effects for testing $\mathrm{v}$ treatments with a control in 3 periods and $6{ }^{\mathrm{t}} \mathrm{C}_{2}$ units.

Example 1

A control balanced three-period COD balanced for first residual effects for comparing 3 test treatments (denoted by 1,2,3) with one control treatment (denoted by 0 ) in 18 experimental units is: 


\begin{tabular}{|c|c|c|c|}
\hline \multirow{2}{*}{$\begin{array}{c}\text { Experimental } \\
\text { Unit }\end{array}$} & \multicolumn{3}{|c|}{ Period } \\
\cline { 2 - 4 } & i & ii & iii \\
\hline i & 0 & 1 & 2 \\
\hline ii & 0 & 1 & 3 \\
\hline iii & 0 & 2 & 1 \\
\hline iv & 0 & 2 & 3 \\
\hline v & 0 & 3 & 1 \\
\hline vi & 0 & 3 & 2 \\
\hline vii & 1 & 0 & 2 \\
\hline viii & 1 & 0 & 3 \\
\hline ix & 2 & 0 & 1 \\
\hline x & 2 & 0 & 3 \\
\hline xi & 3 & 0 & 1 \\
\hline xii & 3 & 0 & 2 \\
\hline xiii & 1 & 2 & 0 \\
\hline xiv & 1 & 3 & 0 \\
\hline xv & 2 & 1 & 0 \\
\hline xvi & 2 & 3 & 0 \\
\hline xvii & 3 & 1 & 0 \\
\hline xviii & 3 & 2 & 0 \\
\hline
\end{tabular}

the variances estimates of contrasts pertaining to test versus control treatments for direct and residual treatment effects. Table 1 shows a list of designs for comparing $\mathrm{t}(\leq 10)$ test treatments with $\mathrm{c}(=1)$ control treatment in $\mathrm{p}(\leq 10)$ periods, $\mathrm{n}(\leq 100)$ units, along with variances.

Table 1 also shows that the designs are variance balanced. It also shows that estimate variances of the contrasts between test versus control treatment of direct effects is less than those of residual effects. Further, variances of the estimates of contrasts between test versus control treatment is less compared to those of test versus test treatments in the case of both direct and residual treatment effects.

Experimental Design 2: Control Balanced Designs Involving Incomplete Treatment Sequences Using MOLS

Append a complete set of ( $\mathrm{t}-1)$ mutually orthogonal Latin squares (MOLS) for prime number t of treatment symbols (Fisher \& Yates, 1963) one after another. This arrangement has $t$ columns and $(\mathrm{t}-1) \times \mathrm{t}$ rows. Delete the last column of the array resulting in $(\mathrm{t}-1)$ columns and $(t-1) \times t$ rows. Replace the first set of $t$ elements in the first column, second set of $t$ elements in the second column, ..., $(\mathrm{t}-1)^{\text {th }}$ set of $t$ elements in the last column, by the control treatment $(\mathrm{t}+1)$. Treating columns as periods and rows as experimental units, the final arrangement results into a control balanced COD for $\mathrm{t}$ tests treatments and 1 control treatment in $\mathrm{p}$ $(=\mathrm{t}-1)$ periods and $(\mathrm{t}-1) \times \mathrm{t}$ units.

A program was developed using SAS software PROC IML for calculating the variance estimates of contrasts among test treatments and

Table 1: List of Control Balanced Designs Involving Treatment Sequences in Three Periods

\begin{tabular}{|c|c|c|c|c|c|c|c|}
\hline S. No. & $\mathrm{t}$ & $\mathrm{p}$ & $\mathrm{n}$ & $\sigma^{-2} \mathrm{~V}_{\mathrm{tt}}$ & $\sigma^{-2} \mathrm{~V}_{\mathrm{tcd}}$ & $\sigma^{-2} \mathrm{~V}_{\mathrm{tt} \mathbf{r}}$ & $\sigma^{-2} \mathrm{~V}_{\text {tcr }}$ \\
\hline 1 & 3 & 3 & 18 & 0.2455 & 0.1860 & 0.4091 & 0.3239 \\
\hline 2 & 4 & 3 & 36 & 0.1741 & 0.1174 & 0.2813 & 0.1992 \\
\hline 3 & 5 & 3 & 60 & 0.1349 & 0.0852 & 0.2143 & 0.1420 \\
\hline 4 & 6 & 3 & 90 & 0.1101 & 0.0667 & 0.1731 & 0.1096 \\
\hline
\end{tabular}




\section{CONTROL BALANCED DESIGNS INVOLVING SEQUENCES OF TREATMENTS}

\section{Example 2}

A control balanced COD for comparing 5 test treatments (denoted by $1,2,3,4,5)$ with one control treatment (denoted by 0 ) in 4 periods and 20 units is:

\begin{tabular}{|c|c|c|c|c|}
\hline \multirow{2}{*}{$\begin{array}{c}\text { Experimental } \\
\text { Unit }\end{array}$} & \multicolumn{4}{|c|}{ Period } \\
\cline { 2 - 5 } i & i & ii & iii & iv \\
\hline ii & 0 & 2 & 3 & 4 \\
\hline iii & 0 & 4 & 5 & 1 \\
\hline iv & 0 & 5 & 1 & 2 \\
\hline v & 0 & 1 & 2 & 3 \\
\hline vi & 1 & 0 & 5 & 2 \\
\hline vii & 2 & 0 & 1 & 3 \\
\hline viii & 3 & 0 & 2 & 4 \\
\hline ix & 4 & 0 & 3 & 5 \\
\hline x & 5 & 0 & 4 & 1 \\
\hline xi & 1 & 4 & 0 & 5 \\
\hline xii & 2 & 5 & 0 & 1 \\
\hline xiii & 3 & 1 & 0 & 2 \\
\hline xiv & 4 & 2 & 0 & 3 \\
\hline xv & 5 & 3 & 0 & 4 \\
\hline xvi & 1 & 5 & 4 & 0 \\
\hline xvii & 2 & 1 & 5 & 0 \\
\hline xviii & 3 & 2 & 1 & 0 \\
\hline xix & 4 & 3 & 2 & 0 \\
\hline xx & 5 & 4 & 3 & 0 \\
\hline & & & & \\
\hline
\end{tabular}

Table 2 shows a list of designs has been prepared for $\mathrm{t}$ test treatments and $\mathrm{c}(=1)$ control treatment, where $t$ is a prime number less than 15. As shown, the designs are partially variance balanced with an underlying varying circular association scheme for test versus test comparisons. Hence, average variance was computed for such comparisons for both the cases of direct $\left(\sigma^{-2} \overline{\mathrm{V}}_{\mathrm{tt}{ }^{\prime} \mathrm{d}}\right)$ as well as residual $\left(\sigma^{-2} \bar{V}_{t t^{\prime} r}\right)$ effects. Variances of the estimates of contrasts between test versus control treatment of direct effects is less than those of residual effects (see Table 2). Variances of the estimates of contrasts between test versus control treatment is less compared to those of test versus test treatments in both cases of direct effects as well as residual treatment effects.

Experimental Design 3: Control Balanced Designs Involving Incomplete Sequences of Two Distinct Sets of Treatments

In the $(t-1)$ columns and $(t-1) \times t$ rows arrangement previously obtained with the MOLS method, replace the first set of $t$ elements in the first column by the first control and first set of the last column by the second control, second set of $t$ elements in the second column by the first control and second set of last but one column by the second control and so on. Thus in each set of $t$ rows, $t$ treatments is replaced by the first control in a staircase descending fashion and $\mathrm{t}$ treatments are replaced by the second control in a staircase fashion circularly until each column is replaced by both controls. Treating columns as periods and rows as

Table 2: List Control Balanced Designs Involving Incomplete Sequences of Two Distinct Sets of Treatments

\begin{tabular}{|c|c|c|c|c|c|c|c|}
\hline S. No. & $\mathrm{t}$ & $\mathrm{p}$ & $\mathrm{n}$ & $\sigma^{-2} \overline{\mathrm{V}}_{\mathrm{tt} \mathbf{d}}$ & $\sigma^{-2} \mathrm{~V}_{\mathrm{tcd}}$ & $\sigma^{-2} \overline{\mathrm{V}}_{\mathrm{tt} \mathbf{r}}$ & $\sigma^{-2} \mathrm{~V}_{\text {tcr }}$ \\
\hline 1 & 5 & 4 & 20 & 0.2122 & 0.1582 & 0.2954 & 0.2248 \\
\hline 2 & 7 & 6 & 42 & 0.0733 & 0.0610 & 0.0902 & 0.0754 \\
\hline 3 & 9 & 8 & 72 & 0.0375 & 0.0329 & 0.0434 & 0.0382 \\
\hline 4 & 11 & 10 & 110 & 0.0229 & 0.0206 & 0.0257 & 0.0232 \\
\hline 5 & 13 & 12 & 156 & 0.0155 & 0.0142 & 0.0170 & 0.0156 \\
\hline
\end{tabular}




\section{VARGHESE \& JAGGI}

experimental units, the final arrangement results in a control balanced design involving sequences of treatments for $\mathrm{t}$ test treatments and 2 control treatments in $\mathrm{p}(=\mathrm{t}-1)$ periods and $(\mathrm{t}-1) \times \mathrm{t}$ units.

\section{Example 3}

A control balanced design involving sequences of treatments for comparing 5 test treatments (denoted by $1,2,3,4,5$ ) with 2 control treatments (denoted by $0_{1}$ and $0_{2}$ ) in 4 periods and 20 units is:

\begin{tabular}{|c|c|c|c|c|}
\hline \multirow{2}{*}{$\begin{array}{c}\text { Experimental } \\
\text { Unit }\end{array}$} & \multicolumn{4}{|c|}{ Period } \\
\cline { 2 - 5 } & i & ii & iii & iv \\
\hline i & $0_{1}$ & 2 & 3 & $0_{2}$ \\
\hline ii & $0_{1}$ & 3 & 4 & $0_{2}$ \\
\hline iii & $0_{1}$ & 4 & 5 & $0_{2}$ \\
\hline iv & $0_{1}$ & 5 & 1 & $0_{2}$ \\
\hline v & $0_{1}$ & 1 & 2 & $0_{2}$ \\
\hline vi & 1 & $0_{1}$ & $0_{2}$ & 2 \\
\hline vii & 2 & $0_{1}$ & $0_{2}$ & 3 \\
\hline viii & 3 & $0_{1}$ & $0_{2}$ & 4 \\
\hline ix & 4 & $0_{1}$ & $0_{2}$ & 5 \\
\hline x & 5 & $0_{1}$ & $0_{2}$ & 1 \\
\hline xi & 1 & $0_{2}$ & $0_{1}$ & 5 \\
\hline xii & 2 & $0_{2}$ & $0_{1}$ & 1 \\
\hline xiii & 3 & $0_{2}$ & $0_{1}$ & 2 \\
\hline xiv & 4 & $0_{2}$ & $0_{1}$ & 3 \\
\hline xv & 5 & $0_{2}$ & $0_{1}$ & 4 \\
\hline xvi & $0_{2}$ & 5 & 4 & $0_{1}$ \\
\hline xvii & $0_{2}$ & 1 & 5 & $0_{1}$ \\
\hline xviii & $0_{2}$ & 2 & 1 & $0_{1}$ \\
\hline xix & $0_{2}$ & 3 & 2 & $0_{1}$ \\
\hline xx & $0_{2}$ & 4 & 3 & $0_{1}$ \\
\hline & & & \\
\hline
\end{tabular}

Table 3 shows a list of designs prepared for comparing $t$ test treatments with $c(=2)$ control treatments, where $t$ is a prime number less than 15 . These designs are partially balanced based on varying circular association scheme for test versus test comparisons pertaining to direct as well as residual effects of treatments. Hence average variance was calculated for these comparisons in case of direct $\left(\sigma^{-2} \bar{V}_{t t^{\prime} d}\right)$ as well as residual $\left(\sigma^{-2} \bar{V}_{t t^{\prime} r}\right)$ effects.

Table 3 shows that the variances of estimates of contrasts between test versus control treatment of direct effects is less than those of residual effects. Also, that variances of estimates of the contrasts between test versus control treatment is less as compared to those of test versus test treatments in both the cases.

\section{References}

Aggarwal, M. L., Deng, L-Y, \& Jha, M. K. (2004). Some new residual treatment effects designs for comparing test treatments a control. Journal of Applied Statistics, 31(9), 1065-1081.

Aggarwal, M. L., \& Jha, M. K. (2009). Constructions of residual treatment effects designs for comparing test treatments with a control. Communications in Statistical Theory and Methods, 38(15), 2567-2577.

Fisher, R. A., \& Yates, F. (1963). Statistical tables for Biological. Agricultural and Medical Research, 6, 88-89.

Hedayat, A. S., \& Zhao, W. (1990). Optimal two-period repeated measurements designs. Annals of Statistics, 18(4), 1805-1816.

Hedayat, A. S., \& Yang, M. (2005). Optimal and efficient crossover designs for comparing test treatments with a control treatment. Annals of Statistics, 33(2), 915-943.

Koch, G. G., Amara, I. A., Brown, Jr, B. W., Colton, T., \& Gillings, D. B. (1989). A twoperiod cross-over design for the comparison of two active treatments and placebo. Statistics in Medicine, 8, 487-504.

Majumdar, D. (1988). Optimal repeated measurement designs for comparing test treatments with a control. Communications in Statistical Theory and Methods, 17(11), 36873703.

Pigeon, J. G., \& Raghavarao, D. (1987). Cross-over designs for comparing treatments with a control. Biometrika, 72(2), 321-328.

Ting, P.C. (2002). Optimal and efficient repeated measurements designs for comparing test treatments with a control. Metrika, 56(3), 229-238. 
CONTROL BALANCED DESIGNS INVOLVING SEQUENCES OF TREATMENTS

Table 3: List of Control Balanced Designs Involving Incomplete Sequences of Two Distinct Sets of Treatments

\begin{tabular}{|c|c|c|c|c|c|c|c|}
\hline S. No. & $\mathrm{t}$ & $\mathrm{p}$ & $\mathrm{n}$ & $\sigma^{-2} \overline{\mathrm{V}}_{\mathrm{tt} \mathrm{d}}$ & $\sigma^{-2} \mathrm{~V}_{\mathrm{tcd}}$ & $\sigma^{-2} \overline{\mathrm{V}}_{\mathrm{tt} \mathbf{r}}$ & $\sigma^{-2} \mathrm{~V}_{\text {tcr }}$ \\
\hline 1 & 5 & 4 & 20 & 0.3204 & 0.2210 & 0.4663 & 0.3065 \\
\hline 2 & 7 & 6 & 42 & 0.0960 & 0.0719 & 0.1176 & 0.0887 \\
\hline 3 & 9 & 8 & 72 & 0.0446 & 0.0363 & 0.0516 & 0.0421 \\
\hline 4 & 11 & 10 & 110 & 0.0261 & 0.0222 & 0.0292 & 0.0249 \\
\hline 5 & 13 & 12 & 156 & 0.0171 & 0.0150 & 0.0188 & 0.0165 \\
\hline
\end{tabular}

Williams, E. J. (1949). Experimental designs balanced for the estimation of residual effects of treatments. Australian Journal of Scientific Resources, A2, 149-168.
Yang, M., \& Park, M. (2007). Efficient crossover designs for comparing test treatments with a control treatment when $\mathrm{p}=3$. Journal of Statistical Planning and Inference, 137(6), 2056-2067. 